\title{
Polymyxin $P$ is the active principle in suppressing phytopathogenic Erwinia spp. by the biocontrol rhizobacterium Paenibacillus polymyxa M-1
}

Ben Niu ${ }^{1,2,7}$, Joachim Vater ${ }^{3}$, Christian Rueckert ${ }^{4}$, Jochen Blom ${ }^{4}$, Maik Lehmann ${ }^{5}$, Jin-Jiang Ru ${ }^{1}$, Xiao-Hua Chen², Qi Wang ${ }^{1 *}$ and Rainer Borriss ${ }^{2,6^{*}}$

\begin{abstract}
Background: Nine gene clusters dedicated to nonribosomal synthesis of secondary metabolites with possible antimicrobial action, including polymyxin and fusaricidin, were detected within the whole genome sequence of the plant growth-promoting rhizobacterium (PGPR) Paenibacillus polymyxa M-1. To survey the antimicrobial compounds expressed by $\mathrm{M}-1$ we analyzed the active principle suppressing phytopathogenic Erwinia spp.

Results: P. polymyxa M-1 suppressed the growth of phytopathogenic Erwinia amylovora Ea 273, and E. carotovora, the causative agents of fire blight and soft rot, respectively. By MALDI-TOF mass spectrometry and reversed-phase high-performance liquid chromatography (RP-HPLC), two antibacterial compounds bearing molecular masses of 1190.9 Da and 1176.9 Da were detected as being the two components of polymyxin $P$, polymyxin $P_{1}$ and $P_{2}$, respectively. The active principle acting against the two Erwinia strains was isolated from TLC plates and identified by postsource decay (PSD)-MALDI-TOF mass spectrometry as polymyxin $\mathrm{P}_{1}$ and polymyxin $\mathrm{P}_{2}$. These findings were corroborated by domain structure analysis of the polymyxin $(p m x)$ gene cluster detected in the $\mathrm{M}-1$ chromosome which revealed that corresponding to the chemical structure of polymyxin P, the gene cluster is encoding D-Phe in position 6 and L-Thr in position 7.

Conclusions: Identical morphological changes in the cell wall of the bacterial phytopathogens treated with either crude polymyxin $\mathrm{P}$ or culture supernatant of $\mathrm{M}-1$ corroborated that polymyxin $\mathrm{P}$ is the main component of the biocontrol effect exerted by strain M-1 against phytopathogenic Erwinia spp.
\end{abstract}

\section{Background}

The plant growth-promoting rhizobacterium Paenibacillus polymyxa, formerly known as Bacillus polymyxa [1], can promote plant growth by producing indole-3-acetic acid (IAA) [2] and volatile compounds [3]. It is also known for controlling plant-parasitic nematodes [4,5] and fungal phytopathogens including Fusarium oxysporum [6], Fusarium graminearum [7], Aspergillus niger [8], Penicillium expansum [9], Leptosphaeria maculans [10], Phytophthora palmivora and Pythium aphanidermatum [11]. P. polymyxa has been recently used to control bacterial phytopathogens

\footnotetext{
* Correspondence: wangqi@cau.edu.cn; rainer.borriss@rz.hu-berlin.de ${ }^{1}$ The MOA Key Laboratory of Plant Pathology, Department of Plant Pathology, College of Agronomy and Biotechnology, China Agricultural University, Beijing 100193, PR China

${ }^{2}$ Institut für Biologie/Bakteriengenetik, Humboldt Universität Berlin, Berlin 10115, Germany

Full list of author information is available at the end of the article
}

such as Xanthomonas campestris [12], and X. axonopodis [13]. The antagonistic effect of $P$. polymyxa against phytopathogens is mainly due to its capability to produce antimicrobial substances, such as peptide antibiotics and antimicrobial proteins. $P$. polymyxa can produce several kinds of peptide antibiotics, including polymyxins [14-22], gavaserin and saltavidin [23], jolipeptin [24], gatavalin [25] and fusaricidins $[26,27]$.

Polymyxins which are known for their strong inhibiting effects against gram-negative bacteria have been used to treat multidrug-resistant gram-negative bacteria [28] and to prevent septic shock [29]. The molecular structure of polymyxin is comprised of a cyclic peptide chain and a hydrophobic tail. Each member of polymyxins differs in the structures of fatty acids and the variations in the amino acid residues [30]. Polymyxins are synthesized by the nonribosomal peptide synthetase (NRPS) mechanism [31]. 
To date, two giant gene clusters responsible for synthesis of polymyxin A [28], and polymyxin B [32] are known.

Among the 202 bacterial strains isolated from surface sterilized wheat plants collected from Beijing and Henan Province, China, one strain designated M-1 was selected due to its inhibiting effect against fungal phytopathogens. Growth of wheat was also enhanced in the presence of this strain indicating its plant growth promoting activity [33]. The whole genome of $P$. polymyxa M-1 has been sequenced, and nine giant gene clusters involved in non-ribosomal synthesis of antimicrobial lipopeptides and polyketides have been detected [34]. Due to its rich spectrum of secondary metabolites with antimicrobial action, $P$. polymyxa $\mathrm{M}-1$ is a good candidate for biocontrolling fire blight, a serious disease in apple and pear caused by Erwinia amylovora. Previously, we have shown that the polyketide difficidin and the dipeptide bacilysin produced by Bacillus amyloliquefaciens suppress growth of E. amylovora [35]. Here, we report that $P$. polymyxa M-1 synthesizes two components of polymyxin $\mathrm{P}$, polymyxin $\mathrm{P}_{1}$ and $\mathrm{P}_{2}$, which are efficient against E. amylovora. Moreover, the corresponding polymyxin synthetase gene cluster in M-1 was identified and further characterized by domain analysis as being different from the $p m x$ gene clusters encoding polymyxin $\mathrm{A}$ and $\mathrm{B}$, respectively.

\section{Results}

\section{Characterization of $\mathrm{M}-1$}

Culture supernatants of M-1 suppressed growth of several bacteria, including the human opportunistic pathogen Pseudomonas aeruginosa (Table 1). Remarkably, growth of phytopathogenic E. amylovora Ea 273 and E. carotovora was strongly inhibited (Figure 1). M-1 was identified as $P$. polymyxa by its $16 \mathrm{~S}$ rDNA sequence (gb accession: FR727737) and by physiological and biochemical features. The motile, rod-shaped and sporeforming bacterium was facultative anaerobic, was positive

\begin{tabular}{lc}
$\begin{array}{l}\text { Table } 1 \text { Antibacterial activity of Paenibacillus polymyxa } \\
\text { M-1 culture supernant determined in agar diffusion test }\end{array}$ \\
\hline Indicator strains & Diameter of the inhibition zone (mm) \\
\hline Erwinia amylovora Ea 273 & 21.5 \\
Erwinia carotovora & 20 \\
Escherichia coli K12 & 18 \\
Pseudomonas aeruginosa & 23 \\
Streptococcus faecalis & 7 \\
Micrococcus luteus & 22.5 \\
Bacillus megaterium & 14.5 \\
Bacillus subtilis 168 & 7.5 \\
Bacillus amyloliquefaciens FZB42 & 6 \\
\hline
\end{tabular}

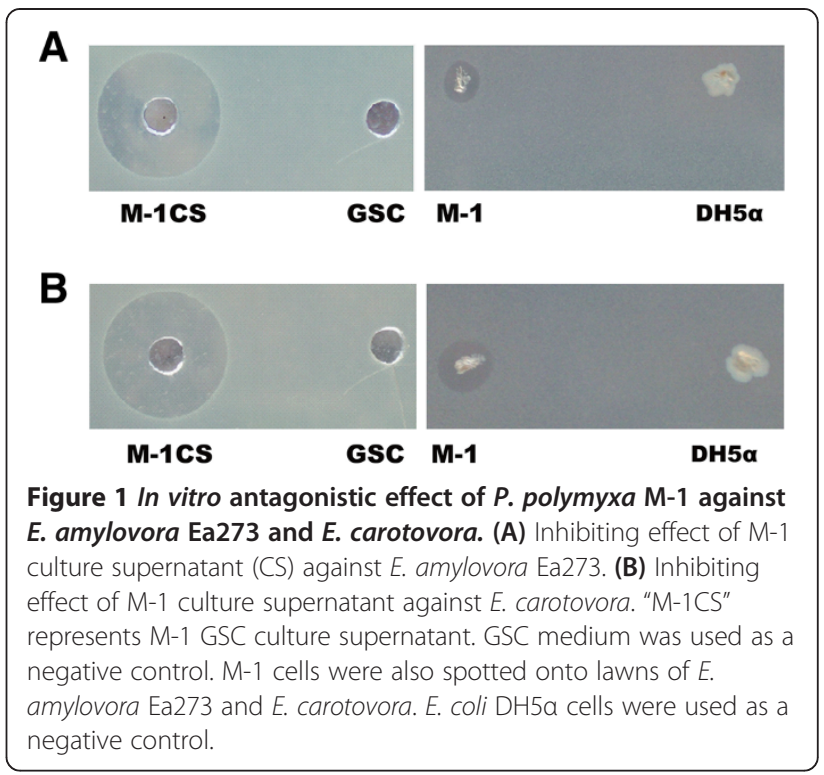

in the Voges-Proskauer reaction (acetylmethylcarbinol), able to hydrolyze starch and to utilize glucose, xylose, glycerol, and mannitol, but did not grow at sodium chloride concentrations exceeding 5\%. The whole genome sequence of M-1 (gb accession: HE577054.1) displayed close similarity to the sequences of plant-associated $P$. polymyxa strains SC2 [36] and E681 [3], respectively.

\section{Detection and structural characterization of polymyxin $\mathbf{P}$}

The metabolites produced by $P$. polymyxa $\mathrm{M}-1$, possessing antagonistic activities against E. amylovora Ea273 and E. carotovora were identified by matrix-assisted laser desorption ionization-time of flight mass spectrometry (MALDI-TOF-MS) in combination with bioautography. Antibacterial activities were detected in both cell-surface extracts and a GSC culture supernatant of M-1. Cell surface extracts were prepared by extraction of cells picked from agar plates with $70 \%$ acetonitrile/ $0.1 \%$ trifluoroacetic acid [37]. By MALDI-TOF-MS, two prominent series of mass peaks were detected, ranging from $\mathrm{m} / z=883.1$ to 983.5 (series 1 ) and from $m / z=1177.9$ to 1267.9 (series 2) (Figure 2A), respectively. Members of series 1 were attributed to the well-known fusaricidins (unpublished data), a family of lipodepsipeptides exhibiting potent antifungal activities [38]. The compounds of series 2 (Figure 2B) were investigated by MALDI-TOF-MS in more detail. Two metabolites were detected, of which the protonated forms showed masses of $m / z=1191.9$ and $m / z=1177.9$. The other mass peaks of series 2 could be attributed to the alkali adducts of these compounds as indicated in Figure 2B. Their structures were determined by postsource decay (PSD)-MALDI-TOF-MS analysis and compared with 

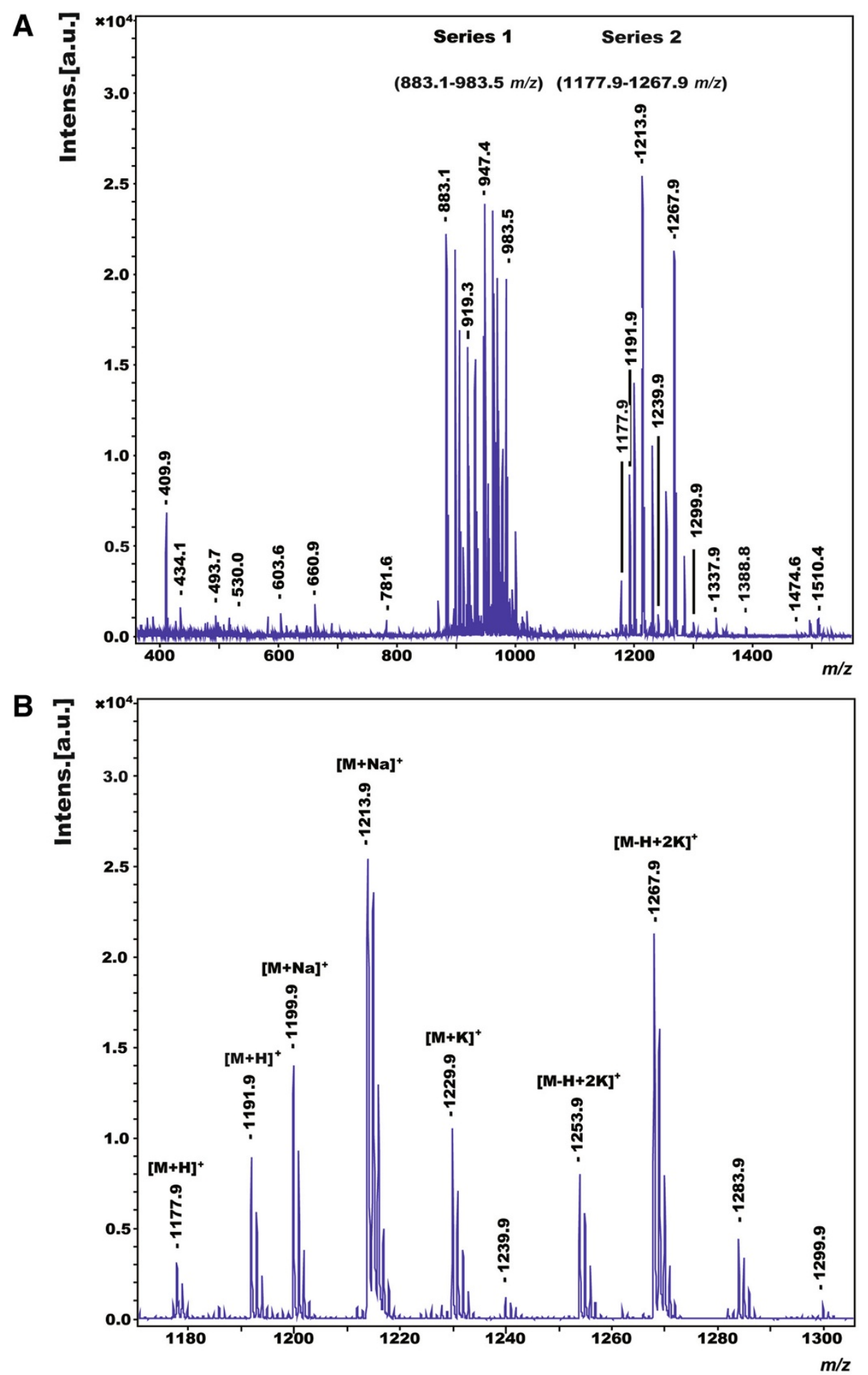

Figure 2 MALDI-TOF-MS analysis of $P$. polymyxa M-1 secondary metabolites. (A) Culture supernatant of M-1 grown in GSC medium containing fusaricidin (series 1 , from $m / z=883.1$ to 983.5 ) and polymyxin $P$ (series 2 , from $m / z=1177.9$ to 1267.9 ) derived mass peaks.

(B) Extended view of the mass peaks $\mathrm{m} / \mathrm{z}$ forming series 2. Two polymyxin P metabolites $[\mathrm{M}+\mathrm{H}]^{+} \mathrm{m} / \mathrm{z} 1177.9$ and 1191.9 , and their alkali adducts $[\mathrm{M}+\mathrm{Na}]^{+} \mathrm{m} / \mathrm{z} 1199.9$ and 1213.9, $\left[\mathrm{M}+\mathrm{K}^{+} \mathrm{m} / \mathrm{z}\right.$ 1229.9, and $[\mathrm{M}-\mathrm{H}+2 \mathrm{~K}]^{+} \mathrm{m} / \mathrm{z} 1253.9$ and 1267.9 were distinguished. The nature of the trailing peaks next to the peaks of interest is unknown. 
the fragment spectrum of polymyxin B which was commercially available (Figure 3).

The fragment spectra of both the M-1 products of series 2 and polymyxin $B$ as the reference revealed the presence of imino ions of threonine $(\mathrm{m} / z=74.1)$ and phenylalanine $(m / z=120.3)$ as well as dipeptide ions of Dab-Dab $(2,4$ diaminobutyric acid, $m / z=201.4)$, DabThr $(m / z=202.2)$ and Dab-Phe $(m / z=248.3)$. The M-1 -products and polymyxin $\mathrm{B}$ differed in the dipeptide fragments Phe-Thr $(m / z=249.4)(M-1)$ and Phe-Leu $(m /$ $z=261.1$ ) (polymyxin B). These comparative nearest neighbour relationships imply that the compounds of series 2 belong to the polymyxin family which are well known antibiotics produced by $P$. polymyxa. This conclusion was confirmed by fragment analysis using PSDMALDI-TOF mass spectrometry. Figure 3 shows the peptide sequence of the M-1 metabolite with the mass number of $m / z=1191.9$ and the polymyxin B with $m / z$ $=1203.9$ as well as of their sodium adducts. In each case the best results were accomplished in mass spectrometric sequencing, when a break of the peptide bond between residue 4 and the $\mathrm{C}$-terminus is assumed. The sequence of the resulting linearized peptide follows residues 1-10. The most significant and almost complete sequence information was obtained in the case of the $b_{n}$ - ions, when fragmentation starts between $\mathrm{Dab}_{1}$ and $\mathrm{Thr}_{2}$. For the $\mathrm{Y}_{\mathrm{n}}$ - ions the best results were achieved, when fragmentation begins between $\mathrm{Thr}_{10}$ and $\mathrm{Dab}_{9}$. In this way $-\mathrm{Dab}_{1}-\mathrm{Thr}_{2}-\mathrm{Dab}_{3}-\mathrm{Dab}_{4}-\mathrm{Dab}_{5}-\mathrm{Phe}_{6}-\mathrm{Thr}_{7}-\mathrm{Dab}_{8}-$ $\mathrm{Dab}_{9}-\mathrm{Thr}_{10^{-}}$was determined as the peptide sequence of the two M-1 - metabolites of series 2, which can be attributed to polymyxin P containing Phe, Thr and Dab in a molecular ratio of $1: 3: 6$ [14]. In this way, these metabolites could be identified as two isomers of polymyxin $\mathrm{P}$, designated as polymyxin $\mathrm{P}_{1}$ and $\mathrm{P}_{2}$. The mass spectrum of the reference compound polymyxin $\mathrm{B}$ also showed two mass peaks at $m / z=1189.3$ (B1) and 1203.9 (B2). They were attributed to two variants of polymyxin

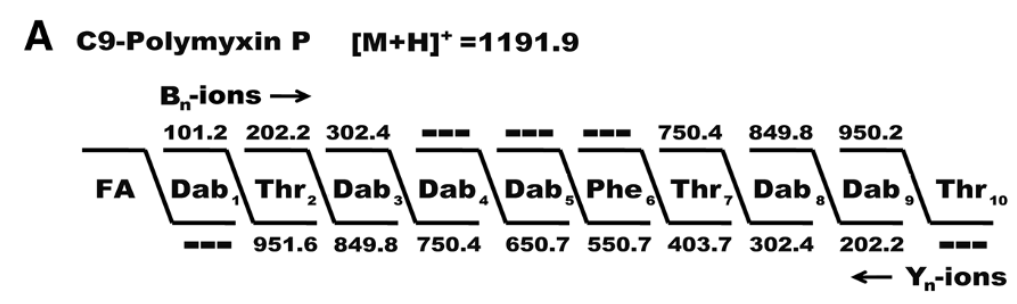

C9-Polymyxin P $[\mathrm{M}+\mathrm{Na}]^{+}=1213.9$

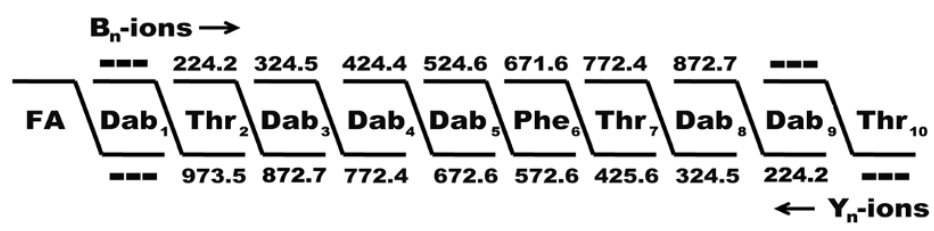

B C9-Polymyxin B $[M+H]^{+}=1203.9$

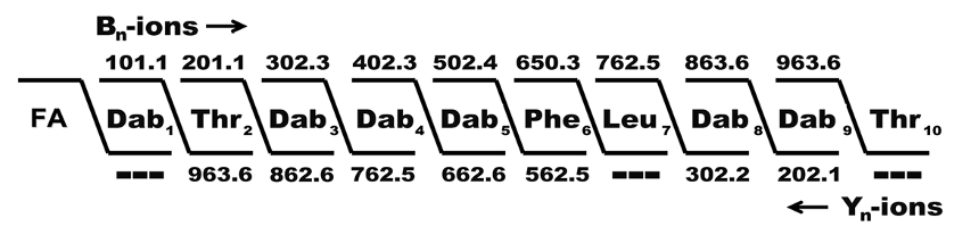

C9-Polymyxin B $[\mathrm{M}+\mathrm{Na}]^{+}=1225.9$

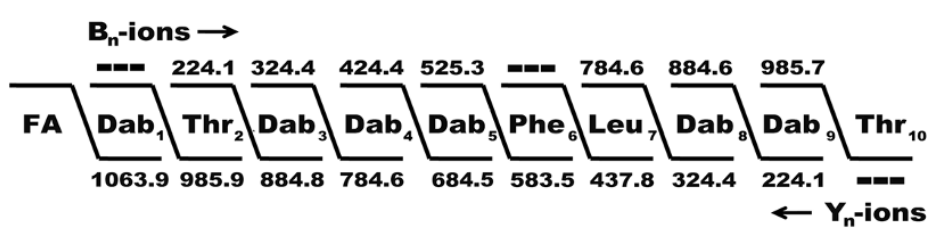

Figure 3 In situ structural analysis of polymyxins by PSD-MALDI-TOF mass spectrometry. (A) Lipopeptide produced by P. polymyxa M-1 (with $\mathrm{m} / \mathrm{z}$ of 1191.9 and 1213.9); (B) commercial polymyxin B (with $\mathrm{m} / \mathrm{z}$ of 1203.9 and 1225.9) used as the reference. The structures were derived from a series of $\mathrm{N}$ - and C-terminal fragments [bn - and $\mathrm{Yn}$-ions]. FA, fatty acid. 
$\mathrm{B}$ differing in their fatty acid component, which is either an iso-octanoyl $\left(\mathrm{C}_{8} \mathrm{H}_{15} \mathrm{O}\right)$ or a 6-methyloctanoyl (anteisononanoyl, $\mathrm{C}_{9} \mathrm{H}_{17} \mathrm{O}$ ) residue [21,32]. By comparison with polymyxin $\mathrm{B}$ and other members of the polymyxin family, we conclude that polymyxin $\mathrm{P}_{1}$ and $\mathrm{P}_{2}$ from strain $\mathrm{M}-1$ contain the same fatty acid residues consistent with the data reported by Kimura et al. for polymyxin P [14].

\section{The anti-Erwinia activity of polymyxin $\mathrm{P}$ produced by P. polymyxa M-1}

In order to identify the compounds which suppress the growth of E. amylovora Ea273 and E. carotovora in M-1 GSC culture, the supernatant was subjected to thin layer chromatography (TLC) in combination with bioautography [39] (Figure 4). One spot exhibiting antibacterial activity was observed at $\mathrm{R}_{f} 0.36$ (Figure $4 \mathrm{~A}$ ) which was identical with that of polymyxin P [14]. It was scraped off from the thin layer plate. The silica gel powder obtained was extracted with methanol, and the extract was analyzed by MALDI-TOF-MS. The obtained mass spectrum ranging from $m / z=850$ to 1350 (Figure 4B) indicates the same mass peaks at $m / z=1199.9, \mathrm{~m} / z=1213.9, \mathrm{~m} / z=1239.9, \mathrm{~m} /$ $z=1253.9$ and $m / z=1268.0$ as previously been detected for series 2 in Figure 2. From these results we conclude, that polymyxin $\mathrm{P}_{1}$ and $\mathrm{P}_{2}$ represent the active compounds inhibiting growth of the Erwinia test strains. There were no mass signals pointing to fusaricidines $(\mathrm{m} / z=850-1000)$ or other metabolites showing antibacterial activity (Figure 4B). Thus, polymyxin $\mathrm{P}$ was proven to be an anti-Erwinia metabolite which was produced by $\mathrm{M}-1$.

To corroborate these results, a GSC culture supernatant of $\mathrm{M}-1$ was fractionated by reversed-phase high-performance liquid chromatography (RP-HPLC) (Figure 5A). Fifteen fractions were obtained. The fraction appearing at a retention time of 2 displayed antagonistic effects against the growth of the two phytopathogenic Erwinia indicator strains (Figure 5B). This fraction was analyzed by high-performance liquid chromatography electrospray ionization mass spectrometry (HPLC-ESI-MS). Two peaks were detected at $m / z=1191.8$ and $m / z=1177.9$, which also correspond to the two isomers of polymyxin P [14] (Figure 5C).

\section{Morphological changes of Erwinia strains caused by treatment with crude polymyxin $\mathbf{P}$}

The effect of the crude polymyxin P prepared by RP-HPLC described above against two phytopathogenic Erwinia strains was studied by scanning electron microscopy (SEM). Cell surfaces of both untreated E. amylovora Ea 273 and E. carotovora appeared smooth without any visible irregularities (Figure 6A and D). However, dense projections were observed on cell surfaces of the two phytopathogens treated with crude polymyxin $\mathrm{P}$ (Figure $6 \mathrm{~B}$ and $\mathrm{E}$ ) or

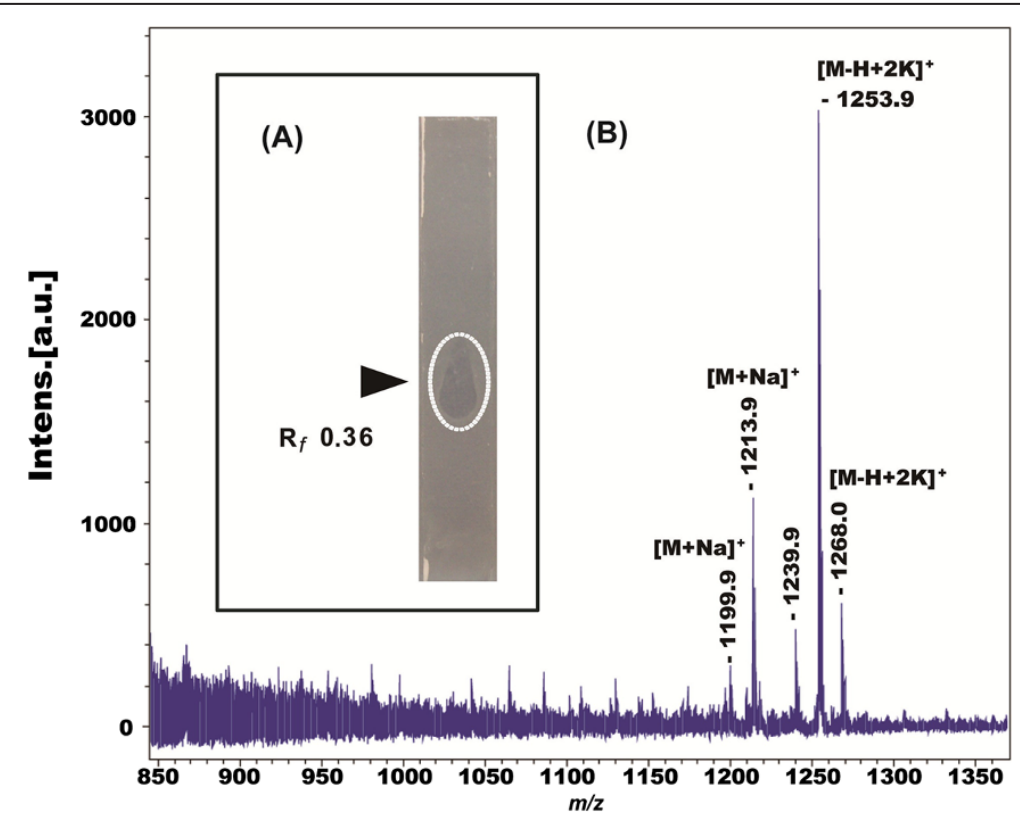

Figure 4 Detection of the anti-Erwinia metabolite produced by P. polymyxa M-1. (A) Detection of the antibacterially acting metabolite by bioautography. Supernatants prepared from strain M-1 grown in GSC medium for $36 \mathrm{~h}$ were separated by TLC and sandwiched with indicator strain E. carotovora. The inhibiting band at $R_{f} 0.36$ was circled. (B) MALDI-TOF-MS analysis of the antibacterial compounds detected by bioautography. 


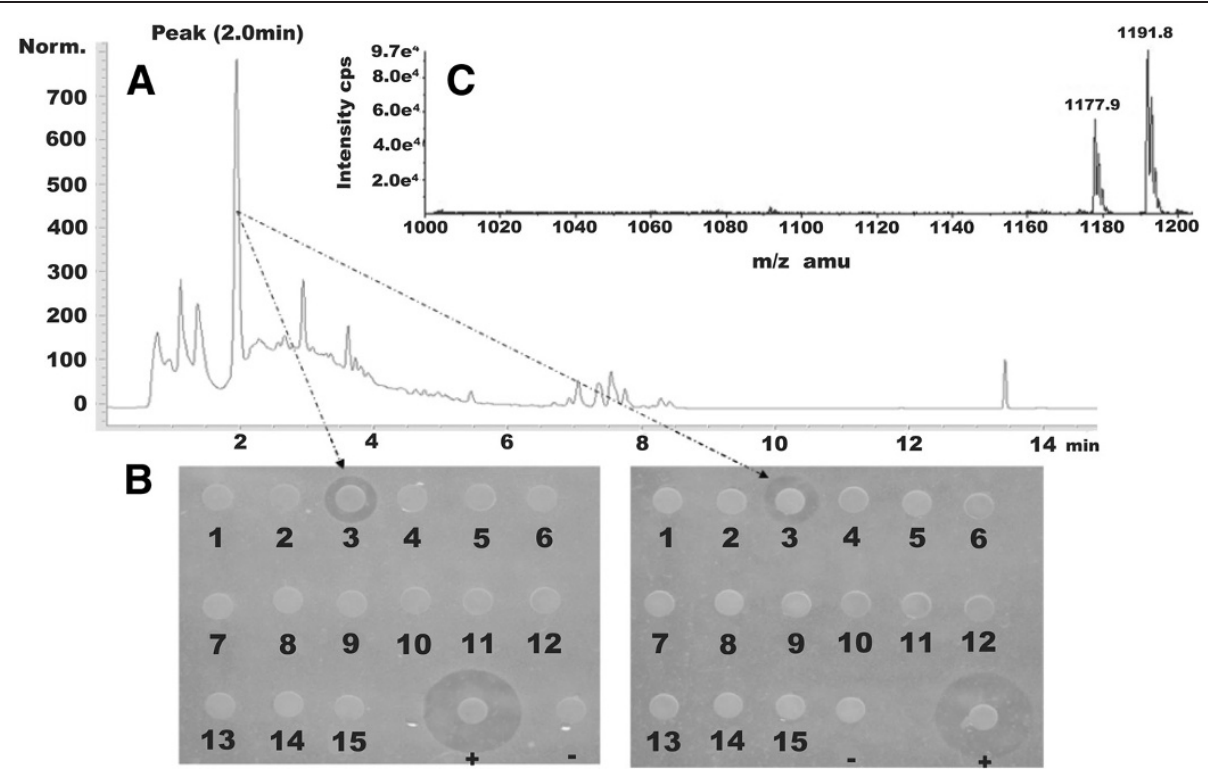

Figure 5 RP-HPLC analysis and antibacterial activity test of fractions. (A) RP-HPLC (HPLC type: Agilent 1100) analysis of M-1 GSC culture supernatant using a Luna $\mathrm{C}_{18}$ column $(100 \AA 150 \times 4.6 \mathrm{~mm}$, Phenomenex, Aschaffenburg, Germany). (B) Antibacterial activity test of HPLC fractions of M-1 GSC culture supernatant. 15 paper discs loaded with HPLC fractions were put onto LB agar mixed with the two Erwinia strains. The numbers below paper discs indicate different fractions. Fractions 3 corresponding to the peak at retention time 2 min in the M-1 culture supernatant HPLC chromatogram showed antagonistic effects against the growth of E. amylovora Ea273 (left) and E. carotovora (right). " + " represents positive control, discs loaded with M-1 culture supernatant, while "-" represents negative control, discs loaded with sterile water. (C) HPLC-ESI-MS analysis of fraction 3.

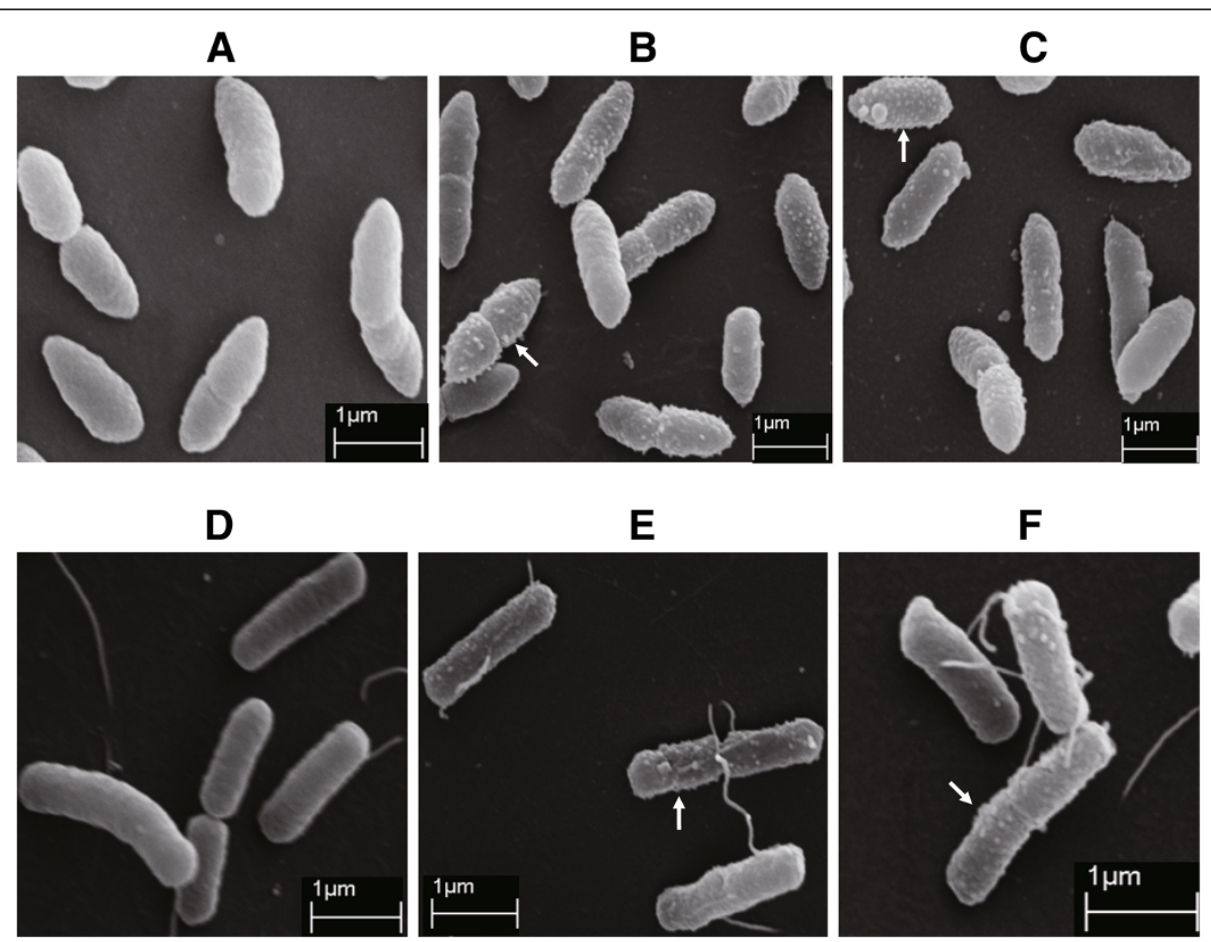

Figure 6 Morphological changes of the Erwinia strains treated with polymyxin P and M-1 GSC culture supernatant. (A) Untreated E. amylovora Ea273; (B) E. amylovora Ea273 treated with crude polymyxin P; (C) E. amylovora Ea273 treated with M-1 GSC culture supernatant; (D) Untreated E. carotovora; (E) E. carotovora treated with crude polymyxin P; (F) E. carotovora treated with M-1 GSC culture supernatant. Protrusions on cell surfaces of E. amylovora Ea273 and E. carotovora treated with crude polymyxin P and M-1 GSC culture supernatant were marked by arrows. 
cell- free supernatant prepared from M-1 GSC culture (Figure $6 \mathrm{C}$ and $\mathrm{F}$ ) suggesting that polymyxin $\mathrm{P}$ caused the same morphological change as M-1 GSC culture supernatant did. Similar morphological changes were also found on cell surfaces of Salmonella typhimurium, Escherichia coli B [40], Chlamydia psittaci [41] and Pseudomonas aeruginosa treated with polymyxin B or E [42].

The observed morphological changes at the surface of the Erwinia cells treated with polymyxin support an action mechanism in which polymyxin, bound at the lipopolysaccharide component of the outer membrane (OM), does permeabilize the OM [30] and - as shown here - generates visible protrusions.

\section{Characterization of the gene cluster encoding polymyxin biosynthesis in $P$. polymyxa M-1}

The genome of $P$. polymyxa M-1 contains a $41 \mathrm{~kb}$ gene cluster displaying overall identities of $96.41 \%$ to the well characterized polymyxin synthetase gene cluster from $P$. polymyxa E681 [28] and of 91.2\% to that from P. polymyxa PKB1 [32] on the nucleotide sequence level. Corresponding to the $p m x$ gene clusters of E681 and PKB1, the M-1 gene cluster consisted of five open reading frames, $p m x A, p m \times B$, $p m x C, p m x D$ and $p m x E$ (Figure 7A). Three of them, the genes $p m x A, p m x B$ and $p m x E$ were directly involved in non-ribosomal peptide synthesis, while $p m x C$ and $p m x D$ were encoding $\mathrm{ABC}$ transporters (ATPase and permease components).

Domain analysis performed with the NRPSpredictor2 server of the university of Tuebingen [43] revealed that the putative polymyxin synthetase of $\mathrm{M}-1$ comprises ten modules (Figure 7B). Each of them consists of three or four domains, such as A-T-C, A-T-E-C or A-T-TE. However, similar to the $p m x$ gene clusters in $P$. polymyxa PKB1 and $P$. polymyxa E681, the order and arrangement of the NRPS encoding genes was not collinear with the amino acids in the polymyxin end product. PmxA, a polypeptide containing 5010 amino acids, comprised four modules. The substrate specificities of the four adenylation domains (A-domain) were predicted to activate the amino acid substrates D-Phe-6, L-Thr-7, L-Dab-8 and L-Dab-9, respectively. PmxB, a polypeptide consisting of 1102 amino acids, contained the remaining part of the last module including a thioesterase domain (TE-domain), A-T-TE. The A-domain was predicted to activate L-Thr-10. PmxE, a 6312 amino-acid polypeptide, contained five modules responsible for the first five amino acids of polymyxin P. In addition, a N-terminal condensation domain with similarity to starter C-domain simultaneously acylating the first amino acid with a fatty acid tail was identified [44]. The five

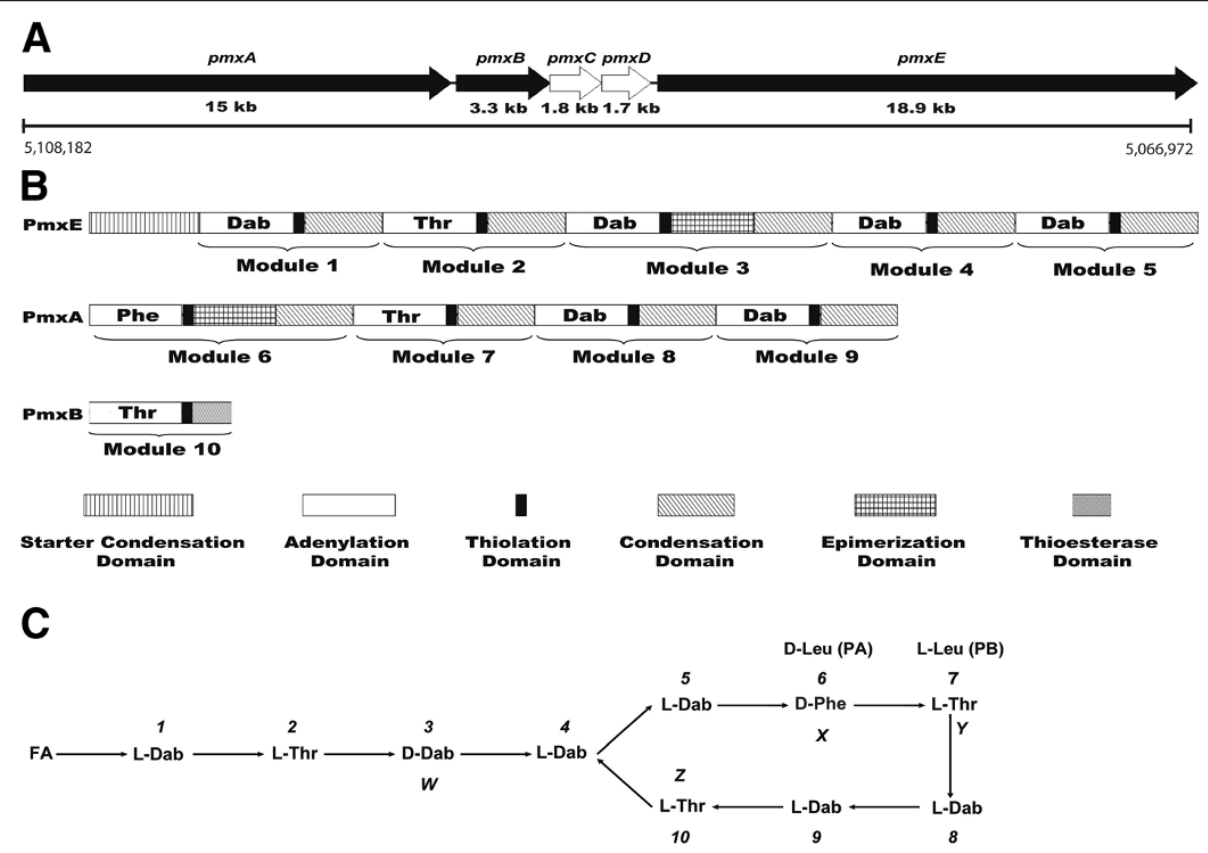

Figure 7 Putative gene cluster for polymyxin biosynthesis in P. polymyxa M-1 and primary structure of polymyxin P. (A) Genetic structure of the $p m x$ genes. Black filled arrows represent NRPS genes, while white arrows represent ABC transporter-like genes. The position of the gene cluster within the chromosome of $\mathrm{M}-1$ is indicated. (B) Domain organization of the putative Pmx enzymes. (C) Primary structure of polymyxin P synthesized in P. polymyxa M-1 derived by bioinformatic and chemical analysis. FA, fatty acid, 6-methyloctanoic acid or isooctanoic acid. "1-10" indicate the ten amino acid moieties. Four variable sites were marked as "W, X, Y and Z", respectively. Phe at the sixth position (X) of polymyxin $\mathrm{P}$ is replaced by Leu at the corresponding position of polymyxin A [28], while Thr at the seventh position ( $Y$ ) of polymyxin $\mathrm{P}$ is substituted by Leu at the corresponding position of polymyxin B [32]. Polymyxin A and polymyxin B are labelled as "PA" and "PB", respectively. 
A-domains were predicted to activate L-Dab-1, L-Thr-2, DDab-3, L-Dab-4, and L-Dab-5, respectively. Therefore, the ten modules were arranged in the gene order $p m x E-p m x A$ $p m x B$ (Figure 7B). There were two epimerization domains (E-domains), occurring in the third and sixth module, which indicated that the third and sixth amino acid of the polymyxin produced by $\mathrm{M}-1$ represented D-forms, D-Dab and D-Phe, respectively. The TE-domain located at the carboxy-terminal region of PmxB was probably responsible for terminating polymyxin synthesis by cyclization and releasing the product. The domain organization analysis of the putative polymyxin synthetase from M-1 implied that the lipopeptide synthesized by the synthetase is identical with polymyxin $\mathrm{P}$ (Figure 7C) [14], which coincides with the results obtained by mass spectrometric analysis. Although there is high overall sequence similarity between the polymyxin gene clusters of $\mathrm{M}-1, \mathrm{E} 681$, and PKB1, the A domains in modules $6(\mathrm{X})$ and $7(\mathrm{Y})$ activate different amino acids. The identity between the amino acid sequences of the sixth modules of polymyxin synthetases of $\mathrm{M}-1$ and E681, activating Phe and Leu, respectively, was only $88 \%$. An even lower identity of $51 \%$ on the amino acid level was found for the A-domains of the seventh module in the polymyxin synthetases from $\mathrm{M}-1$ and $\mathrm{PKB} 1$, activating either Thr or Leu, respectively.

Polymyxin antibiotics are lipopeptides, and as in case of the two other known pmx gene clusters, no genes were found in the vicinity of the $p m x$ gene cluster of $P$. polymyxa M-1 which might be involved in lipidation of the peptide moiety. It is likely that polymyxin synthesis resembles surfactin synthesis, and relies upon lipidation functions encoded elsewhere in the chromosome [32]. Notably, a thioesterase-like gene, pteH (COG3208), bearing a GrsT domain and similar to Bacillus amyloliquefaciens SrfAD (27\% identity), was preceding a giant peptide synthetase gene at 2,508,313 in the genome of M-1. However, the $\mathrm{PteH}$ protein contains no acyltransferase domain and its role in attaching the fatty acid moiety to the polymyxin dekapeptide remains to be elusive.

\section{Discussion}

In this study, we found that growth of two important phytopathogens, E. amylovora Ea273 and E. carotovora was inhibited by M-1. Polymyxin P was identified as being the active principle of $\mathrm{M}-1$. Two lines of evidence supported this finding: (1) M-1 supernatants formed a distinct clearing spot when exposed to bioautography using the Erwinia strains as indicator. When the material isolated from that area was analyzed by MALDI-TOF mass spectroscopy, the mass peaks with $m / z$ of 1199.9 , 1213.9, 1253.9 and 1268.0 indicating alkali adducts of polymyxin $\mathrm{P}$ were detected (Figure 4); (2) a single fraction obtained by HPLC contained the inhibiting activity against bacterial pathogens and also the characteristic mass peaks $m / z$ were indicating the presence of polymyxin $\mathrm{P}$ in this sample (Figure 5).

Polymyxin $\mathrm{P}$ is a peptide antibiotic reported more than 40 years ago, and two species with different hydroxy fatty acids were described. Polymyxin $\mathrm{P}_{1}$ contains anteisononanoic acid, a- $\mathrm{C}_{9}$, and polymyxin $\mathrm{P}_{2}$ isooctanoic acid, $\mathrm{i}-\mathrm{C}_{8}$ [14]. Although its constituent amino acids have been determined as being six Dab, three Thr, and one Phe; to the best of our knowledge, no further investigation about the primary structure of polymyxin $\mathrm{P}$ and the configuration of the constituent amino acids has been performed until now.

Here we established the primary structure of polymyxin P by PSD-MALDI-TOF mass spectrometry (Figure 3). Alterations in comparison to other polymyxin species were detected in two out of the four variable positions of the peptide. A unique Phe residue resided at the sixth position $(\mathrm{X})$, and a Thr residue was found at the seventh position ( $\mathrm{Y}$ ) of polymyxin $\mathrm{P}$. These results were corroborated by bioinformatic analysis of the polymyxin synthetase gene cluster in $M-1$, where the adenylation domains specified the amino acid substrates to be activated (Table 2). The resulting order of amino acids did completely match with the structure for polymyxin P obtained by PSD MALDI-TOF MS (Figure 7C). Whilst this technique did not deliver information about stereochemical configuration of the amino acid moieties, our bioinformatic approach resulted in detection of two epimerization-domains residing in the third and the sixth module (Figure 7B), suggesting the presence of DDab and D-Phe in position 3 and 6 of the polymyxin product, respectively (Figure 7C). The occurrence of DDab in position 3 corresponds with recent findings in polymyxin A [28] and polymyxin B [32]. This is remarkable, since according to literature, these forms of polymyxin are rare and the fact that all three of the polymyxin gene clusters examined to date are from plant-associated strains of $P$. polymyxa isolated for their biocontrol and plant growth promoting activities is relevant for this observation [32].

\section{Conclusions}

Our results support the view that polymyxin $\mathrm{P}$ encoded by the $p m x \mathrm{ABCDE}$ gene cluster is the main compound in the culture filtrate of $P$. polymyxa $\mathrm{M}-1$ in suppressing E. amylovora and E. carotovora, the causative agents of the important plant diseases fire blight and soft rot, respectively. Since the rare polymyxin $\mathrm{P}$ has not been previously used as a clinical agent, in contrast to polymyxin $\mathrm{B}$ and colistin [30], this finding provides a potential option to use polymyxin $\mathrm{P}$ or its producer strain $P$. polymyxa $\mathrm{M}-1$ as an alternative of chemical bactericides to control fire blight, soft rot and other plant diseases caused by gram-negative bacteria. 
Table 2 Specificity-conferring amino acids and homologies of the adenylation domains in polymyxin synthetases of strains M-1, E681, and PKB1

\begin{tabular}{|c|c|c|c|c|c|c|c|c|c|c|c|}
\hline \multirow[t]{2}{*}{ Module/ strain } & \multicolumn{8}{|c|}{ Active site residues in A-domain } & \multirow[t]{2}{*}{ Specified aa } & \multirow[t]{2}{*}{$\%$ aa E681 } & \multirow[t]{2}{*}{$\%$ aa PKB1 } \\
\hline & 235 & 236 & 239 & 278 & 299 & 301 & 322 & 330 & & & \\
\hline \multicolumn{12}{|l|}{ Module 1} \\
\hline $\mathrm{pmxE1/M-1}$ & $\mathrm{D}$ & V & G & $\mathrm{E}$ & । & $S$ & $\mathrm{~S}$ & । & L-Dab & 99 & 99 \\
\hline $\mathrm{pmxE1/E681}$ & $\mathrm{D}$ & V & G & $\mathrm{E}$ & । & $S$ & $S$ & । & L-Dab & & \\
\hline pmxE1/PKB1 & $\mathrm{D}$ & V & W & $E$ & । & $\mathrm{S}$ & S & । & L-Dab & & \\
\hline \multicolumn{12}{|l|}{ Module 2} \\
\hline pmxE2/M-1 & $\mathrm{D}$ & $\mathrm{F}$ & W & $\mathrm{N}$ & । & G & M & V & L-Thr & 99 & 98 \\
\hline pmxE2/E681 & $\mathrm{D}$ & $\mathrm{F}$ & W & $\mathrm{N}$ & । & G & M & V & L-Thr & & \\
\hline pmxE2/PKB1 & D & $\mathrm{F}$ & w & $\mathrm{N}$ & । & G & M & V & L-Thr & & \\
\hline \multicolumn{12}{|l|}{ Module $3(W)$} \\
\hline $\mathrm{pmxE3/M-1}$ & $\mathrm{D}$ & V & G & $E$ & I & $S$ & $S$ & I & D-Dab & 98 & 92 \\
\hline pmxE3/E681 & $\mathrm{D}$ & V & G & $\mathrm{E}$ & I & S & $S$ & । & D-Dab & & \\
\hline pmxE3/PKB1 & $\mathrm{D}$ & V & G & $E$ & I & $S$ & $S$ & । & D-Dab & & \\
\hline \multicolumn{12}{|l|}{ Module 4} \\
\hline pmxE4/M-1 & $D$ & V & G & $\mathrm{E}$ & I & $S$ & A & । & L-Dab & 96 & 96 \\
\hline pmxE4/E681 & $\mathrm{D}$ & V & G & $\mathrm{E}$ & I & $S$ & A & । & L-Dab & & \\
\hline pmxE4/PKB1 & $\mathrm{D}$ & V & G & $E$ & । & $S$ & A & । & L-Dab & & \\
\hline \multicolumn{12}{|l|}{ Module 5} \\
\hline pmxE1/M-1 & $\mathrm{D}$ & V & G & $E$ & I & $S$ & A & 1 & L-Dab & 97 & 89 \\
\hline pmxE1/E681 & $\mathrm{D}$ & V & G & $E$ & I & $S$ & A & I & L-Dab & & \\
\hline pmxE1/PKB1 & $\mathrm{D}$ & V & G & $E$ & । & $S$ & A & । & L-Dab & & \\
\hline \multicolumn{12}{|l|}{ Module $6(X)$} \\
\hline pmxA1/M-1 & $\mathrm{D}$ & A & W & $\mathrm{T}$ & I & A & A & 1 & D-Phe & 88 & 99 \\
\hline pmxA1/E681 & $\mathrm{D}$ & A & w & 1 & V & G & A & । & D-Leu & & \\
\hline $\mathrm{pm} \times \mathrm{A} 1 / \mathrm{PKB} 1$ & $\mathrm{D}$ & A & W & $\mathrm{T}$ & । & A & A & । & D-Phe & & \\
\hline \multicolumn{12}{|l|}{ Module 7 (Y) } \\
\hline pmxA2/M-1 & $\mathrm{D}$ & $\mathrm{F}$ & W & $\mathrm{N}$ & । & G & M & V & L-Thr & 99 & 51 \\
\hline pmxA2/E681 & $\mathrm{D}$ & $\mathrm{F}$ & w & $\mathrm{N}$ & । & G & M & V & L-Thr & & \\
\hline pmxA2/PKB1 & $\mathrm{D}$ & G & $\mathrm{F}$ & $\mathrm{L}$ & L & G & L & V & L-Leu & & \\
\hline \multicolumn{12}{|l|}{ Module 8} \\
\hline pmxA3/M-1 & $D$ & V & G & E & । & $S$ & A & । & L-Dab & 97 & 92 \\
\hline pmxA3/E681 & $\mathrm{D}$ & V & G & E & । & S & A & । & L-Dab & & \\
\hline $\mathrm{pm} \times \mathrm{A} 3 / \mathrm{PKB} 1$ & $\mathrm{D}$ & V & G & $\mathrm{E}$ & I & $S$ & A & । & L-Dab & & \\
\hline \multicolumn{12}{|l|}{ Module 9} \\
\hline pmxA4/M-1 & D & V & G & $E$ & । & $\mathrm{S}$ & A & । & L-Dab & 96 & 91 \\
\hline pmxA4/E681 & $\mathrm{D}$ & V & G & $E$ & I & S & A & । & L-Dab & & \\
\hline pmxA4/PKB1 & $\mathrm{D}$ & V & G & $E$ & I & $S$ & A & I & L-Dab & & \\
\hline \multicolumn{12}{|l|}{ Module $10(Z)$} \\
\hline $\mathrm{pmxB1/M-1}$ & $\mathrm{D}$ & $\mathrm{F}$ & w & $\mathrm{N}$ & I & G & M & V & L-Thr & 97 & 99 \\
\hline $\mathrm{pm \times B1/E681}$ & $\mathrm{D}$ & $\mathrm{F}$ & W & $\mathrm{N}$ & । & G & M & V & L-Thr & & \\
\hline $\mathrm{pm \times B1/PKB1}$ & $D$ & $\mathrm{~F}$ & w & $\mathrm{N}$ & । & G & M & V & L-Thr & & \\
\hline
\end{tabular}

Modules 3 and 6 contained extra epimerization domains which might convert Dab3 and Phe6 to the D-configuration. A-domains in modules $6(X)$ and $7(Y)$ specifying different amino acids in the polymyxins produced by M-1, E681, and PKB1 are underlined. 


\section{Methods}

\section{Bacterial strains and growth conditions}

Strain M-1 isolated from surface sterilized wheat roots in China was kept frozen at $-70 \mathrm{C}$ with $15 \%$ glycerol as a laboratory stock. This strain was cultured in tryptic soy broth (TSB) liquid medium or on tryptic soy broth agar (TSBA) plates (TSB supplemented by $1.5 \%$ agar) at $30^{\circ} \mathrm{C}$ for general purposes or in glucose-starch-CaCO 3 (GSC) medium [45] at $30^{\circ} \mathrm{C}$ for antibacterial activity tests and chemical analysis of polymyxin. M-1 has been deposited in China General Microbiological Culture Collection Center (CGMCC) as strain CGMCC 7581. Other strains used in this study were laboratory stocks obtained from different sources and kept frozen with $15 \%(\mathrm{v} / \mathrm{v})$ glycerol at $-70^{\circ} \mathrm{C}$. They were grown in Luria broth (LB) or on LB agar plates (LB solidified with $1.5 \%$ agar) at $30^{\circ} \mathrm{C}$ (E. amylovora Ea273, E. carotovora and Micrococcus luteus) or $37^{\circ} \mathrm{C}$ (Pseudomonas aeruginosa, Streptococcus faecalis, Bacillus megaterium, Bacillus subtilis 168, Bacillus amyloliquefaciens FZB42 and Bacillus cereus ATCC 14579).

\section{Bacterial identification}

Identification of the strain M-1 was carried out by using $16 \mathrm{~S}$ rDNA sequence analysis as well as by physiological and biochemical characterization. After growing in TSB medium at $30^{\circ} \mathrm{C}$ overnight, the bacteria cells were collected by centrifuging for chromosomal DNA isolation using the standard phenol:chloroform procedure. Then, the 16S rDNA was amplified by PCR with two pairs of primers 63 F (5'CAG GCC TAA CAC ATG CAA GTC-3'), 1387R (5'GGG CGG TGA TGT ACA AGG C'-3) [46], 530 F (5'GTG CCA GCM GCC GCG G-3') and 1494R (5'GGY TAC CTT GTT ACG ACT T-3') [46,47]. The reaction mixture included Taq DNA polymerase, $10 \times$ Taq buffer, forward and reverse primers, each deoxynucleoside triphosphate (dATP, dGTP, dCTP and dTTP) (Beijing Youbo Gene Technology Co., Ltd) and template DNA. Amplifications were performed using a Biometra $\mathrm{T}$ personal 48 thermocycler (Biometra, Goettingen, Germany) with the following cycle conditions: initial activation at $94^{\circ} \mathrm{C}$ for $5 \mathrm{~min} ; 35$ cycles of $94^{\circ} \mathrm{C}$ for $1 \mathrm{~min}, 55^{\circ} \mathrm{C}$ for $30 \mathrm{sec}$, and $72^{\circ} \mathrm{C}$ for $1 \mathrm{~min}$; a final extension at $72^{\circ} \mathrm{C}$ for $10 \mathrm{~min}$. PCR products (100 $\mu \mathrm{L}$ total volume) were analyzed by electrophoresis using a $0.8 \%(\mathrm{w} / \mathrm{v})$ Tris-acetate-EDTA (TAE) agarose gel mixed with ethidium bromide and ultraviolet visualization. PCR products were purified from ethidium bromidestained gels using the DNA product purification Kit (TIANGEN BIOTECH (BEIJING) CO., LTD) and inserted into pMD18-T vectors (TAKARA BIOTECHNOLOGY (DALIAN) CO., LTD). The recombinant plasmids were transformed into E.coli DH5 $\alpha$. DNA sequencing of the plasmids was done by Beijing Youbo Gene Technology Co. Ltd. Nucleotide sequences were assembled and edited with Gap4 which is a part of the STADEN package (http://staden.sourceforge.net/) software. The sequences were compared with those of the reference organisms by Blast search.

\section{Selection of a medium for polymyxin production}

Among the seven media used in our survey, Katznelson and Lochhead (KL) medium [48], Landy medium [49], Landy medium either supplemented with yeast extract, D, L-alanine and phenylalanine (Landy GA) or with yeast extract and phenylalanine (Landy G), GSC medium [45], brain-heart infusion (BHI) medium and tryptic soy broth yeast extract (TSBYE) medium, the GSC medium was optimal for production of polymyxin.

\section{Antibacterial activity assay}

To investigate its antibacterial spectrum, $P$. polymyxa $\mathrm{M}-1$ was grown in GSC medium under aerobic conditions at $30^{\circ} \mathrm{C}$ for $72 \mathrm{~h}$. Then the culture was centrifuged at $6000 \mathrm{rpm}$ at $4^{\circ} \mathrm{C}$ for $10 \mathrm{~min}$ to remove cells. Fresh indicator bacteria plates were prepared for the assay. When the concentration of indicator bacteria grown in LB medium at appropriate temperature was up to $4 \times 10^{7} \mathrm{CFU} / \mathrm{mL}$, $0.5 \mathrm{~mL}$ bacteria suspension was mixed with $20 \mathrm{~mL}$ melting LB agar and cooled below $60^{\circ} \mathrm{C}$ to prepare the plates. $50 \mu \mathrm{L}$ M-1 GSC culture supernatant were loaded into a well punched in indicator bacteria plate which was then incubated at $30^{\circ} \mathrm{C}$ overnight to observe the growth inhibition effect. GSC medium without bacteria was also loaded as a negative control. The diameters of inhibition zones were then measured and recorded.

The inhibiting activity of M-1 against E. amylovora Ea273 and $E$. carotovora was also tested by spotting bacterium on an indicator bacteria plate prepared by the method described above. E. coli DH5 $\alpha$ used as a negative control was also spotted onto the lawn of indicator strains. Then the plates were incubated at $30^{\circ} \mathrm{C}$ overnight to observe the growth inhibition effect.

To analyze the antibacterial activity of the HPLC fractions, a $50-\mu \mathrm{L}$ aliquot of each fraction was loaded onto sterilized paper disks. $50 \mu \mathrm{L}$ M-1 GSC culture supernatant used as a positive control and $50 \mu \mathrm{L}$ sterile distilled water used as a negative control were also loaded. After being air dried in a clean bench, the disks were transferred onto E. amylovora Ea273 and E. carotovora plates prepared by the method described above and incubated at $30^{\circ} \mathrm{C}$ overnight to observe growth inhibition effect.

\section{Separation of antibacterial compounds by RP-HPLC}

The chromatographic system consisted of an Agilent 1100 liquid chromatograph equipped with a diode-array detector (Agilent Technologies, Waldbronn, Germany). Hundred $\mu \mathrm{L}$ M-1 culture supernatant were applied to the RP-HPLC column (Luna C18 $100 \AA 150 \mathrm{~mm} \times 4.6 \mathrm{~mm}$, 
Phenomenex, Aschaffenburg, Germany) and eluted isocratically with $\mathrm{H}_{2} \mathrm{O}$ containing $0.1 \% \mathrm{HCOOH}$ at a flow rate of $1 \mathrm{~mL} / \mathrm{min}$. The obtained fractions were freezedried, dissolved in sterile distilled water and subjected to an antibacterial test described above. The active fraction was subsequently used for high performance liquid chromatography electrospray ionization mass spectrometry (HPLC-ESI-MS) analysis.

\section{Bioautography}

Bioautography was performed as previously described [39]. In short, M-1 GSC culture supernatant was loaded onto an XAD16 (Sigma) resin column which was then washed and eluted with methanol. After being dried by a rotary evaporator, the samples were redissolved in methanol and spotted onto silica gel 60 F254 thin-layer chromatography (TLC) aluminium sheets $(20$ by $20 \mathrm{~cm}$; Merck, Darmstadt, Germany) and separated by TLC using $n-\mathrm{BuOH}: \mathrm{AcOH}$ : $\mathrm{H}_{2} \mathrm{O}=4: 1: 3$ containing $1 / 20$ volume of pyridine as the solvent system. Afterwards, strips of the TLC plates were stuck on the surface of the LB agar containing indicator strains at room temperature for $2 \mathrm{~h}$. The LB agar plates were then incubated at $30^{\circ} \mathrm{C}$ overnight. The inhibition zones documented the positions of the antibacterial compounds separated by TLC. Their $\mathrm{R}_{f}$ values were calculated. The experiments were repeated at least three times. Matrix material from the positions at which the antibacterial compounds were located was scraped from the silica gel, and extracted with methanol. Then the extracts were lyophilized and analyzed by MALDI-TOF-MS.

\section{MS analysis}

Metabolites in culture supernatant of M-1 were investigated by MALDI-TOF-MS. After M-1 was grown in GSC medium at $30^{\circ} \mathrm{C}$ for $72 \mathrm{~h}$, samples for mass spectrometric analysis were taken from the culture supernatant and used for measurements after dilution 1:10 with 50\% acetonitrile: $50 \%$ water containing $0.1 \%$ trifluoroacetic acid (solution A). Samples from the TLC plates were diluted in the same way.

MALDI-TOF-mass spectra were recorded using a Bruker Autoflex instrument equipped with a $337 \mathrm{~nm}$ nitrogen laser for desorption and ionization. A 2- $\mu \mathrm{L}$ aliquot of each sample was mixed with the same volume of matrix solution (a saturated solution of $\alpha$-cyano-4-hydroxycinnamic acid in solution A), spotted on the target, air dried and measured as described previously [50].

Spectra were recorded by positive ion detection in reflector mode. The acceleration and reflector voltages were 19 and $20 \mathrm{kV}$ in pulsed ion extraction mode. A molecular gate of $350 \mathrm{Da}$ improved the measurements by filtering out most matrix ions. PSD-MALDI-TOF-MS of the polymyxins were generated with the same samples. Monoisotopic masses were obtained.

In addition, M-1 GSC culture supernatant and the active fraction were analyzed by an online HPLC (1100 series HPLC system, Agilent Technologies) coupled to a QTRAP 2000 mass spectrometer (Applied Biosystems) using a Luna $\mathrm{C}_{18} 100 \AA 50 \times 1 \mathrm{~mm}$ column (Phenomenex). Samples were applied to HPLC-ESI-MS by isocratic elution with $\mathrm{H}_{2} \mathrm{O}$ containing $0.1 \%$ formic acid at a flow rate of $60 \mu \mathrm{L} / \mathrm{min}$ in $10 \mathrm{~min}$. MS analysis was performed in positive ion mode with a mass window ranging from $m / z$ 500-1400.

\section{Polymyxin treatment}

The Erwinia strains were treated with crude polymyxin $\mathrm{P}$ by the method described previously [51] with some modification. The crude polymyxin P (final concentration: $20 \mu \mathrm{g} / \mathrm{mL}$ ) or GSC culture supernatant of M-1 (final concentration: $1 \%(\mathrm{v} / \mathrm{v}))$ was added to LB cultures of the Erwinia strains at $\mathrm{OD}_{600 \mathrm{~nm}}$ of 0.1 . After being inoculated at $28^{\circ} \mathrm{C}$ for $2 \mathrm{~h}$, the suspensions were centrifuged at $4000 \mathrm{rpm}$ for $5 \mathrm{~min}$ to collect bacteria which were then washed two times before observation by SEM.

\section{Scanning electron microscopy}

For analysis by SEM, cells were spinoculated on poly-lysine coated cover glasses and fixed with $2.5 \%$ glutaraldehyde $/ 2 \%$ para-formaldehyde in $100 \mathrm{mM}$ cacodylate buffer ( $\mathrm{pH}$ 7.4) at $4^{\circ} \mathrm{C}$ overnight. After fixation cells were rinsed three times for 10 minutes with $100 \mathrm{mM}$ cacodylate buffer, postfixed for $3 \mathrm{~h}$ in 1\% osmiumtetroxide, rinsed again three times for 10 minutes with $100 \mathrm{mM}$ cacodylate buffer and dehydrated through an ethanol series. After critical point drying, cells were coated with gold and analyzed on an LEO 1430 scanning electron microscope.

\section{Competing interests}

The authors declare that they have no competing interests.

\section{Authors' contributions}

BN carried out the main experiments, data analysis and wrote a manuscript draft. JV performed the mass spectrometric and chemical analysis and revised the manuscript. CR carried out the genome sequencing and assembling. XHC participated in experimental design and revised the manuscript. JB provided genome sequence database support. ML performed the SEM observation. JJR participated in the manual annotation of the genome sequence. QW guided experimental design. RB guided experimental design, performed data analysis and annotation and wrote the final version of the manuscript. All authors read and approved the final manuscript.

\section{Acknowledgements}

We are very thankful for technical support in preparing SEM pictures by Mrs. Drescher. We are indebted to Professor D. Naumann and Dr. P. Lasch from the Robert Koch - Institut, Berlin, making available for us the Bruker Autoflex instrument to perform the MALDI-TOF measurements. Financial support for the project was obtained in frame of the competence network Genome Research on Bacteria (GenoMikTransfer: "PATHCONTROL") and the ChineseGerman collaboration program by the German Ministry for Education and Research, BMBF, is gratefully acknowledged. Q.W. and B.N. are grateful for 
financial support given by the "program for Changjiang scholars and innovative research team in university" (IRT1042). R.B. was supported by the EU-FP7-funded project "BIOFECTOR".

\section{Author details}

${ }^{1}$ The MOA Key Laboratory of Plant Pathology, Department of Plant Pathology, College of Agronomy and Biotechnology, China Agricultural University, Beijing 100193, PR China. ${ }^{2}$ Institut für Biologie/Bakteriengenetik, Humboldt Universität Berlin, Berlin 10115, Germany. ${ }^{3}$ Institut für Chemie Technische Universität Berlin, Berlin 10623, Germany. ${ }^{4}$ Computational Genomics, Center for Biotechnology (CeBiTec) Universität Bielefeld, Bielefeld D-33594, Germany. ${ }^{5}$ Institut für Biologie/Molekulare Parasitologie, Humboldt Universität Berlin, 10115 Berlin, Germany. ${ }^{6}$ ABiTEP GmbH, 12489 Berlin, Germany. ${ }^{7}$ Present address: Department of Microbiology and Immunobiology, Harvard Medical School, Boston, MA 02115, USA.

Received: 19 February 2013 Accepted: 3 June 2013

Published: 18 June 2013

\section{References}

1. Ash C, Priest FG, Collins MD: Molecular identification of rRNA group 3 bacilli (Ash, Farrow, Wallbanks and Collins) using a PCR probe test. Anton Leeuw 1993, 64:253-260.

2. Holl FB, Chanway CP, Turkington R, Radley RA: Response of crested wheatgrass (Agropyron cristatum L.), perennial ryegrass (Lolium perenne) and white clover (Trifolium repens L.) to inoculation with Bacillus polymyxa. Soil Biol BiocheM 1988, 20:19-24.

3. Kim JF, Jeong H, Park SY, Kim SB, Park YK, Choi SK, Ryu CM, Hur CG, Ghim SY, Oh TK, et al: Genome sequence of the polymyxin-producing plantprobiotic rhizobacterium Paenibacillus polymyxa E681. J Bacteriol 2010, 192:6103-6104.

4. Khan Z, Kim SG, Jeon YH, Khan HU, Son SH, Kim YH: A plant growth promoting rhizobacterium, Paenibacillus polymyxa strain GBR-1, suppresses root-knot nematode. Bioresour Technol 2008, 99:3016-3023.

5. Son SH, Khan Z, Kim SG, Kim YH: Plant growth-promoting rhizobacteria, Paenibacillus polymyxa and Paenibacillus lentimorbus suppress disease complex caused by root-knot nematode and fusarium wilt fungus. J App/ Microbiol 2009, 107:524-532.

6. Dijksterhuis J, Sanders M, Gorris LG, Smid EJ: Antibiosis plays a role in the context of direct interaction during antagonism of Paenibacillus polymyxa towards Fusarium oxysporum. J Appl Microbiol 1999, 86:13-21.

7. He J, Boland GJ, Zhou T: Concurrent selection for microbial suppression of Fusarium graminearum, Fusarium head blight and deoxynivalenol in wheat. J Appl Microbiol 2009, 106:1805-1817.

8. Haggag WM, Timmusk S: Colonization of peanut roots by biofilm-forming Paenibacillus polymyxa initiates biocontrol against crown rot disease. J Appl Microbiol 2008, 104:961-969.

9. Zhou WW, Huang JX, Niu TG: Isolation of an antifungal Paenibacillus strain HT16 from locusts and purification of its medium-dependent antagonistic component. J Appl Microbiol 2008, 105:912-919.

10. Beatty PH, Jensen SE: Paenibacillus polymyxa produces fusaricidin-type antifungal antibiotics active against Leptosphaeria maculans, the causative agent of blackleg disease of canola. Can J Microbiol 2002, 48:159-169.

11. Timmusk S, Van West P, Gow NA, Huffstutler RP: Paenibacillus polymyxa antagonizes oomycete plant pathogens Phytophthora palmivora and Pythium aphanidermatum. J Appl Microbiol 2009, 106:1473-1481.

12. Mageshwaran V, Walia S, Annapurna K: Isolation and partial characterization of antibacterial lipopeptide produced by Paenibacillus polymyxa HKA-15 against phytopathogen Xanthomonas campestris pv. phaseoli M-5. World J Microb Biot 2012, 28:909-917.

13. Hahm MS, Sumayo M, Hwang YJ, Jeon SA, Park SJ, Lee JY, Ahn JH, Kim BS, Ryu CM, Ghim SY: Biological control and plant growth promoting capacity of rhizobacteria on pepper under greenhouse and field conditions. J Microbiol 2012, 50:380-385.

14. Kimura Y, Murai E, Fujisawa M, Tatsuki T, Nobue F: Polymyxin P, new antibiotics of polymyxin group. J Antibiot 1969, 22:449-450.

15. Martin NI, Hu H, Moake MM, Churey JJ, Whittal R, Worobo RW, Vederas JC: Isolation, structural characterization, and properties of mattacin (polymyxin M), a cyclic peptide antibiotic produced by Paenibacillus kobensis M. J Biol Chem 2003, 278:13124-13132.
16. Orwa JA, Govaerts C, Busson R, Roets E, Van Schepdael A, Hoogmartens J: Isolation and structural characterization of colistin components. J Antibiot 2001, 54:595-599.

17. Parker WL, Rathnum ML, Dean LD, Nimeck MW, Brown WE, Meyer E: Polymyxin F, a new peptide antibiotic. J Antibiot 1977, 30:767-769.

18. Shoji J, Hinoo H, Wakisaka Y, Koizumi K, Mayama M, Matsuura S: Isolation of two new polymyxin group antibiotics. (Studies on antibiotics from the genus Bacillus. XX). J Antibiot 1977, 30:1029-1034.

19. Shoji J, Kato T, Hinoo $H$ : The structure of polymyxin $S_{1}$ (Studies on antibiotics from the genus Bacillus. XXI). J Antibiot 1977, 30:1035-1041.

20. Shoji J, Kato $T$, Hinoo $H$ : The structure of polymyxin $T_{1}$ (Studies on antibiotics from the genus Bacillus.XXII). J Antibiot 1977, 30:1042-1048.

21. Withander L, Heding H: Polymyxin B: controlled biosynthesis. J Antibiot 1976, 29:774-775.

22. He Z, Kisla D, Zhang L, Yuan C, Green-Church KB, Yousef AE: Isolation and identification of a Paenibacillus polymyxa strain that coproduces a novel lantibiotic and polymyxin. Appl Environ Microbiol 2007, 73:168-178.

23. Pichard B, Larue JP, Thouvenot D: Gavaserin and saltavalin, new peptide antibiotics produced by Bacillus polymyxa. FEMS Microbiol Lett 1995, 133:215-218.

24. Ito M, Koyama Y: Jolipeptin, a new peptide antibiotic. II. The mode of action of jolipeptin. J Antibiot 1972, 25:309-314.

25. Nakajima N, Chihara S, Koyama Y: A new antibiotic, gatavalin. I. Isolation and characterization. J Antibiot 1972, 25:243-247.

26. Kajimura Y, Kaneda M: Fusaricidin A, a new depsipeptide antibiotic produced by Bacillus polymyxa KT-8. Taxonomy, fermentation, isolation, structure elucidation and biological activity. J Antibiot 1996, 49:129-135.

27. Raza W, Yang X, Wu H, Wang Y, Xu Y, Shen Q: Isolation and characterisation of fusaricidin-type compound-producing strain of Paenibacillus polymyxa SQR-21 active against Fusarium oxysporum f. sp. nevium. Eur J Plant Pathol 2009, 125:471-483.

28. Choi SK, Park SY, Kim R, Kim SB, Lee CH, Kim JF, Park SH: Identification of a polymyxin synthetase gene cluster of Paenibacillus polymyxa and heterologous expression of the gene in Bacillus subtilis. J Bacterio/ 2009, 191:3350-3358.

29. Cruz DN, Perazella MA, Bellomo R, De Cal M, Polanco N, Corradi V, Lentini $P$, Nalesso F, Ueno T, Ranieri VM: Effectiveness of polymyxin B-immobilized fiber column in sepsis: a systematic review. Crit Care 2007, 11:R47.

30. Velkov T, Thompson PE, Nation RL, Li J: Structure - activity relationships of polymyxin antibiotics. J Med Chem 2010, 53:1898-1916.

31. Finking R, Marahiel MA: Biosynthesis of nonribosomal peptides 1. Annu Rev Microbiol 2004, 58:453-488.

32. Shaheen M, Li J, Ross AC, Vederas JC, Jensen SE: Paenibacillus polymyxa PKB1 produces variants of polymyxin B-type antibiotics. Chem Biol 2011, 18:1640-1648

33. Yao $L$, Wang $Q, F u$ XC, Mei RH: Isolation and identification of endophytic bacteria antagonistic to wheat sharp eyespot disease. Chin J Biol Control 2008, 24:53-57.

34. Niu B, Rueckert C, Blom J, Wang Q, Borriss R: The Genome of the plant growth- promoting rhizobacterium Paenibacillus polymyxa M-1 contains nine sites dedicated to nonribosomal synthesis of lipopeptides and polyketides. J Bacteriol 2011, 193:5862-5863.

35. Chen XH, Scholz R, Borriss $M$, Junge $H$, Mögel $G$, Kunz S, Borriss R Difficidin and bacilysin produced by plant-associated Bacillus amyloliquefaciens are efficient in controlling fire blight disease. J Biotechnol 2009, 140:38-44.

36. Ma M, Wang C, Ding $Y$, Li L, Shen D, Jiang $X$, Guan D, Cao F, Chen H, Feng $R$, Wang X, Ge Y, Yao L, Bing X, Yang X, Li J, Du B: Complete genome sequence of Paenibacillus polymyxa SC2, a strain of plant growth-promoting rhizobacterium with broad-spectrum antimicrobial activity. J Bacterio/ 2011, 193:311-312

37. Vater J, Kablitz B, Wilde C, Franke P, Mehta N, Cameotra SS: Matrix-assisted laser desorption ionization-time of flight mass spectrometry of lipopeptide biosurfactants in whole cells and culture filtrates of Bacillus subtilis C-1 isolated from petroleum sludge. Appl Environ Microbiol 2002, 68:6210-6219.

38. Choi S, Park S, Kim R, Lee C, Kim J, Park S: Identification and functional analysis of the fusaricidin biosynthetic gene of Paenibacillus polymyxa E681. Biochem Biophys Res Commun 2008, 365:89-95.

39. Chen XH, Vater J, Piel J, Franke P, Scholz R, Schneider K, Koumoutsi A, Hitzeroth G, Grammel N, Strittmatter AW, et al: Structural and functional 
characterization of three polyketide synthase gene clusters in Bacillus amyloliquefaciens FZB 42. J Bacteriol 2006, 188:4024-4036.

40. Schindler PRG, Teuber M: Action of polymyxin B on bacterial membranes: morphological changes in the cytoplasm and in the outer membrane of Salmonella typhimurium and Escherichia coli B. Antimicrob Agents Chemother 1975, 8:95-104.

41. Matsumoto A, Higashi N, Tamura A: Electron microscope observations on the effects of polymyxin B sulfate on cell walls of Chlamydia psittaci. J Bacteriol 1973, 113:357-364.

42. Koike M, lida K, Matsuo T: Electron microscopic studies on mode of action of polymyxin. J Bacteriol 1969, 97:448-452.

43. Röttig M, Medema MH, Blin K, Weber T, Rausch C, Kohlbacher O: NRPSpredictor2-a web server for predicting NRPS adenylation domain specificity. Nucleic Acids Res 2011, 39(2 suppl.):W362-W367.

44. Rausch C, Hoof I, Weber T, Wohlleben W, Huson DH: Phylogenetic analysis of condensation domains in NRPS sheds light on their functional evolution. BMC Evol Biol 2007, 7:78.

45. Eliasson Lantz A, Jorgensen P, Poulsen E, Lindemann C, Olsson L: Determination of cell mass and polymyxin using multi-wavelength fluorescence. J Biotechnol 2006, 121:544-554.

46. Borneman J, Skroch P, O'Sullivan K, Palus J, Rumjanek N, Jansen J, Nienhuis $\mathrm{J}$, Triplett E: Molecular microbial diversity of an agricultural soil in Wisconsin. Appl Environ Microbiol 1935, 1996:62.

47. Marchesi JR, Sato T, Weightman AJ, Martin TA, Fry JC, Hiom SJ, Dymock D, Wade WG: Design and evaluation of useful bacterium-specific PCR primers that amplify genes coding for bacterial $16 \mathrm{~S}$ rRNA. Appl Environ Microbiol 1998, 64:795-799.

48. Katznelson H, Lochhead AG: Nutritional requirements of Bacillus alvei and Bacillus para-alvei. J Bacteriol 1947, 53:83-88.

49. Landy M, Warren GH, et al: Bacillomycin; an antibiotic from Bacillus subtilis active against pathogenic fungi. Proc Soc Exp Biol Med 1948, 67:539-541.

50. Vater J, Gao X, Hitzeroth G, Wilde C, Franke P: "Whole cell"-matrix-assisted laser desorption ionization-time of flight-mass spectrometry, an emerging technique for efficient screening of biocombinatorial libraries of natural compounds-present state of research. Comb Chem High Throughput Screen 2003, 6:557-567.

51. Lounatmaa K, Makela HP, Sarvas M: Effect of polymyxin on the ultrastructure of the outer membrane of wild Type and polymyxinresistant strains of Salmonella. J Bacterio/ 1976, 127:1400-1407.

doi:10.1186/1471-2180-13-137

Cite this article as: Niu et al:: Polymyxin $\mathrm{P}$ is the active principle in suppressing phytopathogenic Erwinia spp. by the biocontrol rhizobacterium Paenibacillus polymyxa M-1. BMC Microbiology 2013 13:137.

\section{Submit your next manuscript to BioMed Central and take full advantage of:}

- Convenient online submission

- Thorough peer review

- No space constraints or color figure charges

- Immediate publication on acceptance

- Inclusion in PubMed, CAS, Scopus and Google Scholar

- Research which is freely available for redistribution 